\title{
MANAGING THE HEALTH AND SAFETY LEGAL AND PSYCHOLOGICAL RAMIFICATIONS OF COVID-19: AN AUSTRALIAN MULTIDISCIPLINARY PERSPECTIVE
}

\author{
PAUL PHILLIPS ${ }^{1}$, ALENA TITTERTON ${ }^{2} \&$ MICHAEL TOOMA ${ }^{3}$ \\ ${ }^{1}$ Need A Psych, Founder \& Psychologist, Level 20, Darling Park Tower 2, Corner Sussex Street and \\ Druitt Street, Sydney, New South Wales, Australia 2000. ORCID: 0000-0001-7190-5235, Email: \\ paul@needapsych.com \\ ${ }^{2}$ Correspondence author: Clyde \& Co (international law firm), Level 15, 333 George Street, Sydney, New \\ South Wales, Australia, 2000. ORCID: 0000-0002-5336-8664, Email: alena.titterton@clydeco.com \\ ${ }^{3}$ Clyde \& Co (international law firm), Level 15, 333 George Street, Sydney, New South Wales, Australia, \\ 2000. ORCID: 0000-0002-4438-526X, Email: michael.tooma@clydeco.com
}

\begin{abstract}
COVID-19 represents unprecedented challenges for the entire community. Much of Australia's commercial sector has voluntarily deployed strategies to support social distancing ahead of any lock downs. Businesses are working to safely maintain operations and a productive workforce throughout social isolation/distancing for an unknown duration. Yet uncertainty, ambiguity and radical change are breeding grounds for anxiety, stress and helplessness. Conditions that contradict safe mental health practices for work. The Australian perspective includes the cumulative stressors of the bushfires, torrential rains and floods. Each of these stressors was an environmental stressor. But people and businesses knew what to do. The newest cumulative stressor is remote work becoming the norm. Workplaces have often had a mediating effect as a point of social interaction. Legally mandated safe spaces that people could connect and be productive within. There is much research on the connection between
\end{abstract}


social isolation and loneliness. Organisations need to support workers in maintaining social connections, team cohesion and productivity throughout these times. This paper will explore the health and safety legal obligations that apply in this context and outline a practical framework for organisations to contribute to and reinforce a positive state of mental health during the mass remote work experiment.

KEYWORDS: mental health, health and safety law, remote working, COVID-19, domestic violence

\section{BUSINESS AS USUAL (BAU)}

Under Australian health and safety laws, organisations /employers (with the duty holder referred to in most jurisdictions as a person conducting a business or undertaking) are subject to a primary duty of care that requires them to ensure the health and safety of workers so far as is reasonably practicable and to ensure that they do not put other persons at risk in the course of their undertakings. Amongst other things, that requires organisations to provide and maintain safe systems of work and safe working environments. Practically discharging those duties requires a risk management approach, to eliminate hazards and risks where reasonably practicable and then to minimise those risks in accordance with the hierarchy of controls. Determining what is reasonably practicable in the circumstances involves proactively identifying, assessing and controlling reasonably foreseeable hazards and risks.

Health and safety under this framework includes both physical and mental health and safety. Relevantly, the definition of health includes psychological health as well as physical health.

Importantly, the duties apply wherever a worker goes while at work and are not limited to the traditional workplace setting.

The statutory health and safety legal framework also recognises that individuals and not just organisations play an important role in securing positive health and safety outcomes during the course of work and as such place specific personal obligations on officers (senior leaders of the organisations), workers and other persons.

Officers are required to exercise due diligence in ensuring the organisations for which they are officers comply with their obligations under the laws. Due diligence requires officers to engage in a number of proactive steps for health and safety corporate governance under 6 elements, one of which is a requirement to ensure there are appropriate resources and processes in place at their organisation for eliminating or minimising health and safety risks.

Workers and other persons are required to take reasonable care for their own health and safety and not adversely affect the health and safety of others while at work. They are also expected to follow the reasonable health and safety instructions of their organisations.

Liability attracts under Australian health and safety laws where these above duties are not met. Prosecutions by health and safety regulators typically occur in the context of failures to adopt the mandatory risk management approach. The offences are 
criminal in nature and are categorised by seriousness with the most seriousness category one offences carrying penalties of AUD 3,000,000 for organisations, AUD 600,000 and/or 5 years imprisonment for officers and AUD 300,000 and/or 5 years imprisonment for workers and other persons.

\section{STRESS IS A REASONABLY FORESEEABLE EVENT IN MANY WORKPLACES}

There is an increasing expectation from regulators that organisations take psychological health seriously and put in place a systematic approach to managing it in their operations. In 2018, Safe Work Australia published national guidance material on work-related psychological health and safety. Commentators welcomed the development but wondered why this issue was relegated to the level of guidance material rather than Code of Practice as is the usual level of guidance issued on specific hazards and risks (such as managing workplace facilities, working with plant or working with electricity).

Information from Safe Work Australia indicates that more than 90\% of psychological injuries are due to stress. Be that from customer interactions for retail staff, to interactions within the office between colleagues or management processes. This stress causes negative responses for people which either aggravate or cause mental illnesses, the most common being Adjustment Disorder, not the often mislabelled Anxiety or Depression. Given how common stress is indicated as a component in the development of an injury it is easy to see it as reasonably foreseeable, i.e., it is not a rare occurrence that cannot be predicted or mitigated. Below we will explore some of the most widely accepted theories of stress and how workplaces can mitigate the detrimental outcomes of placing an employee into a stressed state when operating in business as usual times.

\section{STRESS, ASSUMING FLOW MODEL DESCRIPTION, IS MITIGATED BY TRAINING}

Csikszentmihalyi's work on Flow $(1975,1991,1996,1997)$ has been taken up by many workplaces as part of the positive psychology underpinning prevalent Wellness and Welfare packages. The first edition of this work was and is most relevant to workplaces today as it does not combine his later work on autotelic personalities with Flow. For this reason, this section will draw on the first edition version that included micro and macro flow and did not include any personality concepts. Flow is essentially that state a person enters when their consciousness experiences partial automaticity of their body and thinking system, when things seem to just click, or be in the zone, or time flies when you're having fun. 
Figure 1. Diagram of Flow

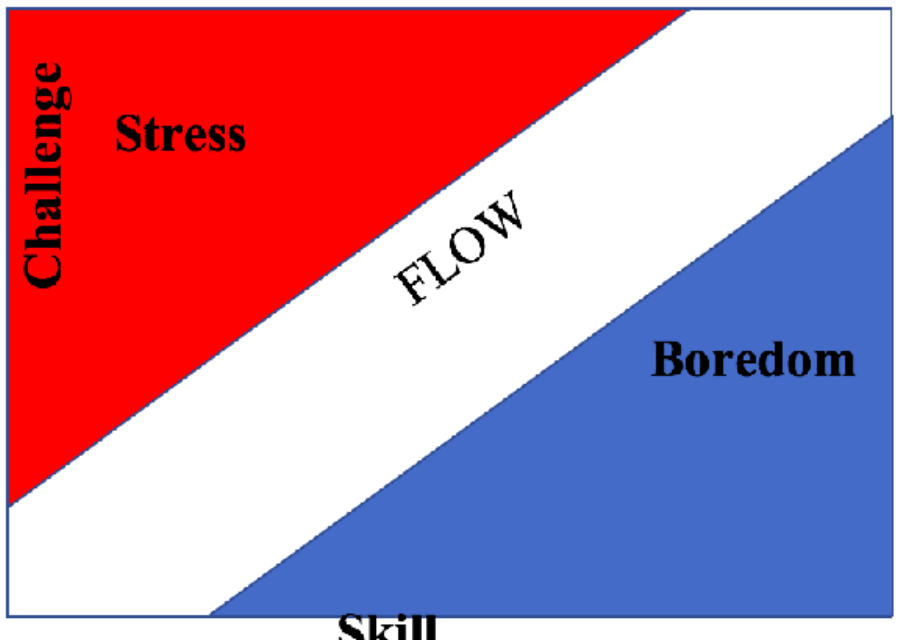

Source: based on the data and information within Csikszentmihalyi's work on Flow (1975, 1991, 1996, 1997)

When Csikszentmihalyi first wrote about the topic he conducted research with various "masters" or "experts". He interviewed chess grand masters to rock climbers. People who excelled at both physical and intellectual pursuits. What was astonishing was the similarity of their descriptions of this experiential state. There are a lot of psychological components described in Flow. Firstly, that it must be experienced. It does not happen outside of experience: rather, it is itself a state of experience, much like intoxication is experienced not just a physiological state.

The second experiential component is the experience of things just clicking, from chess masters describing how the next move just comes to them to rock climbers noticing how their hand just seems to find the right hold. This partial dissociation is similar to that achieved through certain mindfulness practices such as in Mindfulness Based Cognitive Therapy (MBCT) or Acceptance and Commitment Therapy (ACT). This has a huge advantage to businesses as it means workers are working at their peak effectiveness.

The third component that is oft reported is the temporal distortion: that time flies when you are having fun. Again, this is a partial dissociation similar to that achieved through certain mindfulness practices.

The way that Flow is achieved is by having the person's skill in balance with the demand of the task. When these are in balance the person, according to the theory, enters a state of Flow. When the person's skill exceeds the task at hand they instead enter a state of boredom. When the task demand exceeds the skill of the person then they enter a state of stress.

Using this theory in the context of work, if a business is able to balance the skill of the person with the demand of the task, they will enter Flow. If the task is beyond them, they will enter stress. This gives leaders a simple business lever to pull on, to train staff for the tasks they are required to do. 


\section{STRESS, ASSUMING YERKES-DODSON AROUSAL CURVE, IS MITIGATED BY CALMING DOWN OR UP}

Yerkes and Dodson (1908) over 100 years ago documented the relationship between arousal and performance. Language since then has moved on and now we tend to use arousal as a shorthand for sexual arousal, however, this did not relate to that specific form of arousal alone. In more modern times we see the terms "eustress" and "distress" being used. Eustress being the good reaction to "stress" rather than "arousal" and distress being a negative reaction to "stress" rather than "arousal". This is essentially a rebranding of this original theory, where eustress means optimal arousal, and distress means over arousal, and boredom means under arousal.

Figure 2. Yerkes Dodson Arousal Curve

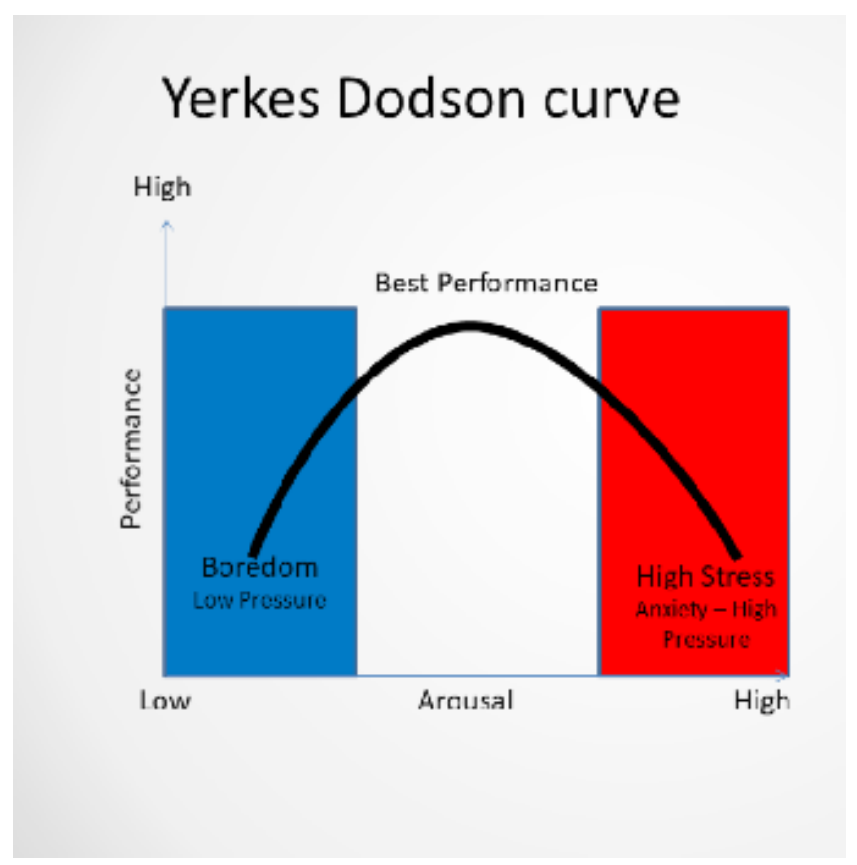

Source: based on the infomration within Yerkes and Dodson (1908)

In this theory of stress the person needs to achieve the optimal arousal state by stimulation, rather than by demand of the task. Anything that is a sensation can be a source of stimulation. This is where sensory modulation becomes important. In school we were all taught about the five senses. Taste, touch, sound, smell, sight, and hearing. However, there are actually over 25 different senses. Sorry to those who believe in ESP it's not the sixth sense it's more like the $28^{\text {th }}$ sense. Some of the senses you were not taught at school include heat perception, cold perception, sharp pain, dull pain and slow aching pain. These are not types of touch, they actually have different nerves in the body, travel up different circuits in the spine and go to different parts of the brain. It gives some explanation as to why people who are in pain (especially if its two types of pain) are already aroused and tip into stress more easily. The two biggest additional senses that are important to be aware of and modulate for are Vestibular and Proprioceptive sensations. 
Vestibular sensations come from your inner ear. It's how your body knows your head is up not down. Spin too many times on a merry go round and you get overstimulated in your vestibular system and often feel nauseous or vomit. Proprioception is from your joints and tells your brain where your body is in time and space without having to look (close your eyes and move your hand around, you still know where your hand is, but it isn't being sensed by any of your five traditional senses).

Combining the sensory knowledge and the Yerkes-Dodson arousal curve is important to work design. If a person has the same stimulation over and over they become under aroused and under perform. This is why some variation of work demands is important. Yet get it wrong and over stimulate the person by having them change too much too often and they become over aroused and tip into stress reactions. This really is a goldilocks type task (not too hot not too cold, getting it just right) for organisations.

\section{STRESS, ASSUMING SENSORY MODULATION MODELS, IS MITIGATED BY REASONABLE ACCOMMODATION}

Sensory modulation is the term applied to giving the neural system the sensations it is built to handle. Where Yerkes-Dodson is about the outside design of the stimulation, sensory modulation is about the unique sensory tolerance profile that each person has and where for some people the design needs to change radically. Imagine two workers in the same sensory environment. If all that was at play here was the Yerkes-Dodson curve then the ideal sensory environment could be assessed and built to maximise optimal arousal. If only it were that simple. Due to neural plasticity, unless those two people had exactly the same journey through their life with the same genetic code, they will have differently wired sensory systems.

One might have loved the swing, snow skiing and waterslides, developing their vestibular system while the other might have disliked those activities and thereby under developing their vestibular system. Now as adults they will have radically different reaction to the same level of vestibular stimulation as they have different neural systems processing the input. Add to this various medical and mental conditions that further alter sensory perception.

This brings about a third lever for business and that is reasonable accommodation for employees. The business must, where feasible, make reasonable accommodations for sensory modulation.

\section{STRESS, ASSUMING SOCIAL INTERACTION MODELS, IS MITIGATED BY GOOD PERSONAL BOUNDARIES CODIFIED IN OFFICE POLICIES AND PROCEDURES}

Much of daily stress comes from interacting with other people. Bullying and harassment claims stem from interactions with others. Many traumas are caused by other people, not natural disasters or pandemics. Inappropriate conduct, such as hazing rituals perpetrated against apprentices, health professionals engaging in sexual activity with patients, or lawyers using money held in trust for gambling debts are also about 
boundary violations. Boundaries help people define what is and is not acceptable. They even change constructs like consent from opt in to opt out, i.e., if two people are friends vs romantically linked what is considered an opt out vs opt in consent can be very different.

Before COVID-19 most people were not working from home all of the time. For most, there was a clear boundary between work and home. However, with digital technologies such as having email on our phones we began to blur this boundary. Now that people are working from home en masse the boundaries are shifting even further and faster than before. Is it now acceptable to come to "work" in a daggy old tracksuit rather than formal business suite? If you are using video conferencing like zoom, skype or facetime is it ok if just the top half is dressed in office attire as that is all the other person sees? Do the normal office policies and procedures apply given you are not in the normal office? For those who did not work from home these were not even questions. The standard office policies and procedures governed this and thereby reduced the possible stress.

\section{STRESS, ASSUMING FORDISM ALIENATION MODELS, IS MITIGATED BY ALIGNING THE PERSON'S ROLE TO THE ORGANISATION'S PURPOSE, VISION, VALUES AND VIRTUES}

Henry Ford invented the motorised or moving production line: a huge leap forward in how products could be manufactured. But this also produced a psychological consequence of alienation. People might well ask what alienation is and why does it matter? In a moving production line a person only has one task that they repeat over and over. They may press a button, or pull a lever, or twist a dial. That could be it. They only have input into that one tiny part of the production process. They may not know how to do the task at a different station along the production line. Let alone see or know how their tiny part actually makes a car, fridge or any other product on the production line. Essentially at that level it may not seem to matter and not be a source of stress. However, this disconnect is distressing to the person.

At 24 hours old the baby can tell the difference between when it touches itself or someone else touches it. That marks the start of the mind's recognition of there is a world outside of me, a me and not me categorisation. By six months old the baby responds differently to things that are objects and things that are people. The baby will attempt to mimic behaviours it sees other people carry out, but not activities it sees objects carry out. This makes a second distinction in the baby's mind for the "not me" category to split into not me and not like me vs not me and like me. These building blocks of psychology become the basis for the person to have a sense of self-efficacy, a sense that "if I try, I can do it". Self-efficacy has been shown through a multitude of research and meta-analyses over more than 50 years to be the one most important psychological factor. What alienation does is it breaks the feedback loop for self-efficacy. It prevents the person from observing what they tried to do actually achieved anything. This changes the "if I try, I can do it" to "if I try, I don't know if I did it or not???"

Understanding this aspect of business and the stress it can cause workers gives 
business a lever of linking the personal effort to the outcome. This often occurs in business by aligning the business vision, via the virtues or values of the business, to the worker's role, and their daily tasks. It is why effective leaders use this lever in staff meetings or gatherings to talk about how the efforts and actions of staff at all levels matter and contribute to the outcome.

\section{THIS GIVES BAU FIVE LEVERS TRAINING, CALMING, ACCOMMODATION, PROCEDURES, ALIGNMENT}

When working within the organisation as a usual environment an effective leader manages staff stress levels by using the five different levers. These can be effectively managed, delegated and monitored within the business to determine their effectiveness and refinement. In so doing the risk of stress becoming a negative impact on the business is reduced. Likewise, the benefit from having staff that are entering Flow, optimally aroused, sensorially modulated, having boundaries, and aligned on how their tasks contribute to the business vision and outcomes maximises staff productivity. It is a win/win for both the staff and the business.

\section{THE FIVE LEVERS ARE GREASED BY RAPPORT}

Leading in times of crisis is in some ways similar to providing therapy to patients. One party is stressed or distressed and the other is trying to help the stressed party function better. If that position is accepted, then it is valuable to consider the literature from therapy that indicates what works. From the outside, the world of mental health would seem to be a proverbial tower of babel situation filled with multiple techniques, jargon and divisions. There is ACT, BT, CBT, CT, MBCT, MBSR, if you prefer acronyms or analytic psychotherapy, gestalt, psychodynamic therapy, process psychology, psychoanalysis, somatic psychotherapy, to name a few. All these various techniques have produced vast volumes of research on their effectiveness and the specific techniques within the style of therapy. What becomes interesting is how much these techniques actually impact the outcome of therapy, and can thereby be applied to the current situation and its leadership needs.

To many disgruntled recipients in their various technique bootcamps the answer from research over fifty years has been resoundingly that the technique is a minor component in the effectiveness of outcome. Much of the literature puts the actual impact of technique at around 15\% of the actual outcome (e.g., Miller. et. al. 1997). That means $85 \%$ has nothing to do with the technique chosen! That $85 \%$ is comprised mostly, around $40 \%$, of the client factors; the experiences, context and resources the person themselves brings to the situation. This is all the aspects of the person that they bring into the situation when they are greeted, the idea that you have to take the worker as you find them (consider the eggshell psyche rule in workers compensation). It is unique to that individual at that time. In the sections above, discussing stress, this is aspects like the personal boundaries, sensory modulation and reasonable accommodations required, and of course the current context of the COVID-19 pandemic. 
The other significant factor, around 30\%, is the relationship between the therapist and the patient. Expectancy is the other main factor, that is, what the patient expects to gain from the process and how the therapist communicates, understands and meets that expectancy.

Figure 3. Factors that Effect Outcomes

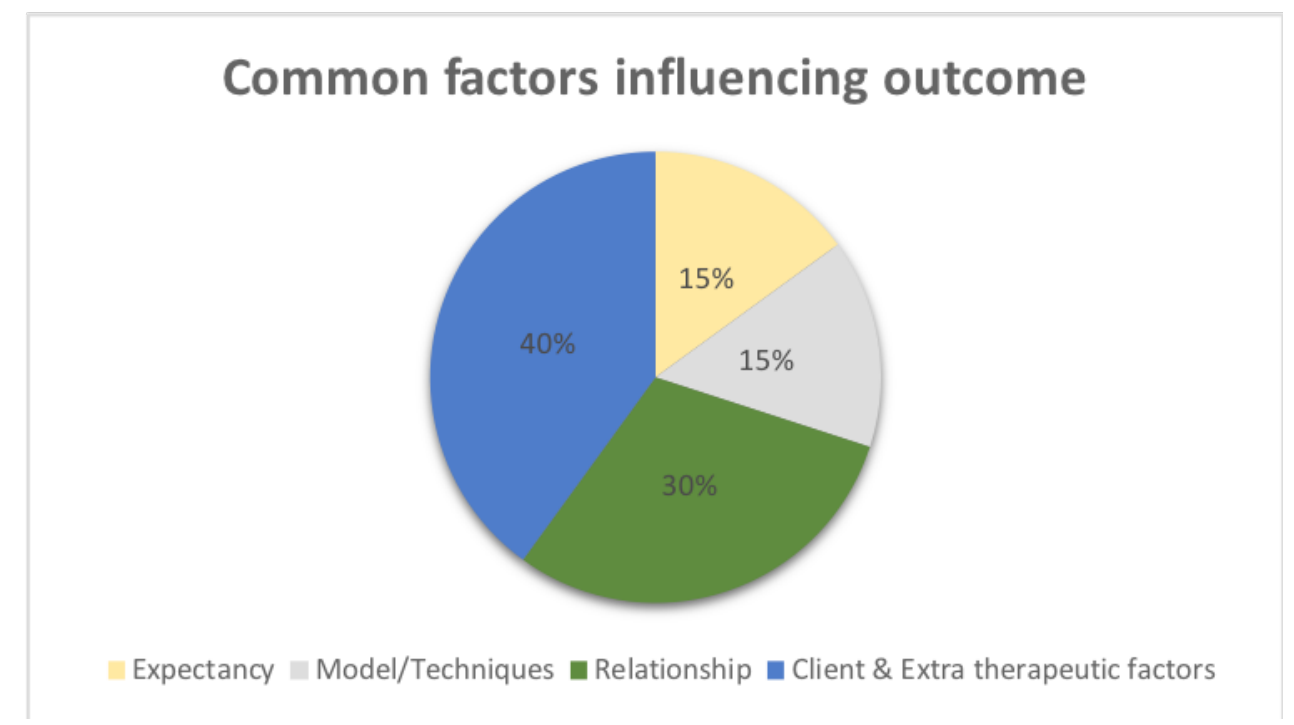

Source: based on the information within Miller et al. (1997).

Applying this knowledge to leadership in Business With COVID (BWC) gives clear priorities to how the leader needs to lead.

The largest aspect that the leader can control (at best) or influence (at worst) is the relationship factors. This is rapport. Establishing rapport early, revisiting it often, and nurturing it through the journey. Rapport can be conceptualised as coming from either a shallow level or a deep level.

The shallow level style of rapport is the one that is often used in sales, like a used car sales yard. The salesperson may ask about some trivial aspect of your world, be it where you live, what sports team you follow, or some upcoming holiday event. Once this is known then the person will make commentary suggesting some shared experience with you. This in turn tricks your mind into thinking that the person is part of your in-group. This social psychology trick then is leveraged as people will naturally tend to make a choice that is consistent with someone else they see as part of their ingroup. It's why peer pressure works. And like magic the salesperson would buy that car too and the next thing you know you have bought the car. The shallow rapport worked for that transactional moment. Deep rapport is different.

Deep rapport is not based on the shallow level of events, sports teams or a holiday. It is based on one of the universal seven emotions discovered by Ekman. Ekman's research showed that there are seven universal emotions experienced and identified by all the people of the world; sad, happy, anger, fear, disgust, contempt and surprise. Deep rapport uses the connection and similarity at this level between the two people. It draws on the leader or therapist's ability to help move the person through the 
Maslow's hierarchy of needs level of love and belonging. Belonging itself can be conceptualised as having hierarchical layers (where 1 is the lowest foundation layer needed to progress) of:

1. Acknowledgement: you exist and I as another person see and hear you.

2. Recognition: you are different to me and have a right to have a different experience to me.

3. Validation: your experience is valid and not a concoction, fabrication or gross exaggeration.

4. Alignment: we can work together on a task that is beneficial to both of us.

5. Acceptance: you are part of the group and not merely needed to achieve the aligned outcome but wanted.

By acknowledging that the person exists and that they have one of the universal emotions the leader has already progressed the person through the first two layers. When the leader acknowledges that they too have had that emotion, or are having that emotion, they are validating the other person. That simple process has already moved the person from feeling isolated and disconnected to feeling that they belong and are ready to begin to align. Using this approach means that the leader can draw on the $30 \%$ of the relationship factors to bring about an effective outcome.

Clear, concise and consistent communication is imperative. It is the way that the leader can set and manage the expectancy of staff, clients and the community. Doing that alone gets you $15 \%$ of the outcome. The expectancy in these situations, that is times of crisis management, has been well established. Consultative processes are disadvantageous as they increase ambiguity and uncertainty. It is an interesting challenge given there are specific legal obligations for worker consultation on health and safety matters under Australian laws that will still apply. Command and control communication, directive yet civil is what is expected by the community. It does not need further research to be understood, it is already understood.

Combining deep rapport and managing the expectancy through clear, concise and consistent communication will activate $45 \%$ of the effective factors. Understanding the inherent client factors of sensory modulation, arousal needs, boundaries and their personal context activates the other $40 \%$. By taking these approaches the leader is able to activate $85 \%$ of the factors that will create a favourable outcome for the person, and by achieving that the business. 
Figure 4. Factors Positively Effected by Leadership Choices

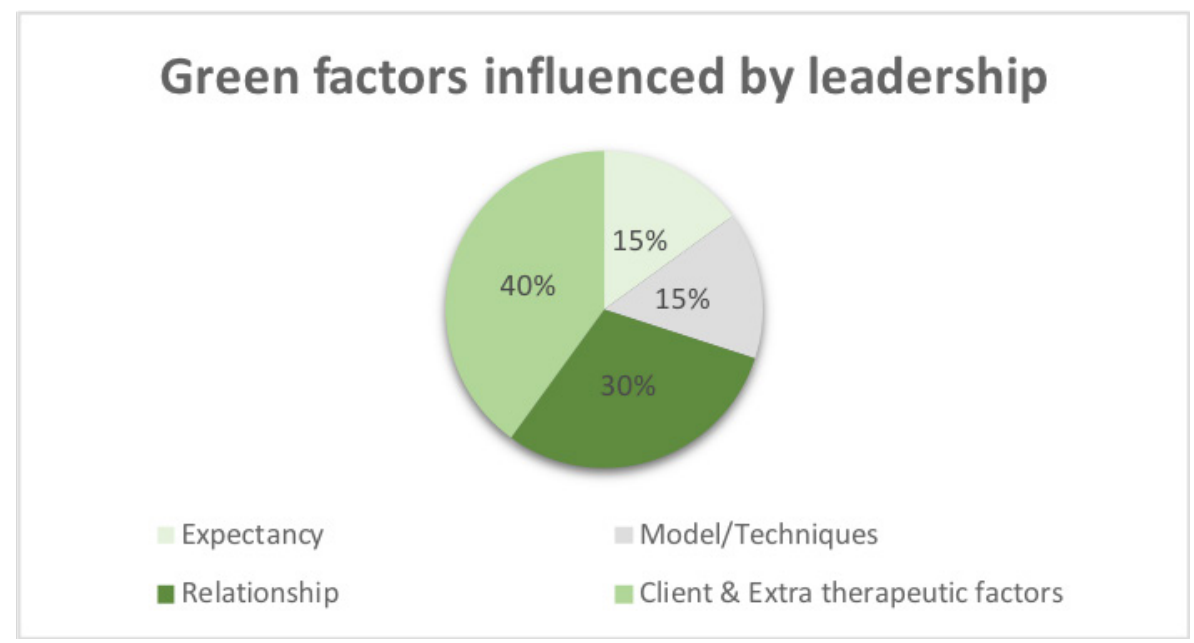

Source: based on the information within Miller et al. (1997).

\section{IS THERE A PSYCHOLOGICAL EQUIVALENT OF PERSONAL PROTECTIVE EQUIPMENT (PPE)?}

Resilience is your and your staff's PPE in these times. Resilience is often spoken about, yet it is important to understand it is a twofold concept. This is because from a clinical perspective resilience is the umbrella term for the factors, yes plural, that impact on both if a person is likely to get a mental illness, predisposing, and that also contribute to their recovery, perpetuating. They are the same ten factors:

(i) Boundaries: ability to set and maintain personal rules of engagement and respect others.

(ii) Determination/grit: ability to complete tasks despite obstacles.

(iii) Emotional Self-efficacy: ability to keep emotions under control and change them as needed.

(iv) General self-efficacy: having confidence that the person can do tasks.

(v) Help-seeking self-efficacy: confidence to seek out and ask for help when needed.

(vi) Learning self-efficacy: confidence to learn new things as needed.

(vii) Mature ego defences: ability to respond to unpleasant information like an adult.

(viii) Mindfulness: ability to be aware and experience the present.

(ix) Physical self-efficacy: confidence to look after own physical health. 
(x) Social self-efficacy: confidence in ability to interact with other people.

Leading with a positive challenge mindset is drawing on various aspects of these ten factors, mostly general self-efficacy, emotional self-efficacy, determination, learning self-efficacy and mindfulness. Being a staff member or contributor in times of crisis, like the COVID-19 pandemic, requires the staff member to draw on the ten factors and mostly, general self-efficacy, help-seeking self-efficacy, boundaries, physical self-efficacy, and determination.

\section{WHAT HAPPENS WHEN YOU DON'T MITIGATE THE STRESSORS?}

As we move further into Business With COVID times it will become increasingly important for businesses to attempt to use the mitigating factors to reduce stress. Below are the three types of consequences that may happen if the business does not mitigate stress during COVID-19. There may be a world of legal and regulatory ramifications for failure to mitigate the stressors. Health and safety regulators may prosecute organisations and their leaders for criminal offences under health and safety laws, there may be claims for compensation in the context of the health and safety laws' victimisation provisions, workers compensation claims for psychological injury, as well as adverse action and general protections claims under the industrial relations regime and often a mix of the above. For some industries, the failures may also trigger notifications to and investigations by relevant professional industry bodies. Some health and safety related issues may also lead to class actions and other actions in tort. In recent years we have seen a trend in Australia towards the use of multiple legal mechanisms and fora in the context of psychological injury. For example, a workers compensation claim will often be made simultaneously with an anonymous call by a claimant to a regulator to notify of a concern for psychological risk management at a particular organisation, triggering investigation and enforcement action by a heath and safety regulator that is in turn used as a pressure point for leverage in negotiations by claimants.

\section{STRESS DIATHESIS MODEL OF MENTAL HEALTH}

The stress diathesis model of mental illness is a biopsychosocial theory that there is a relationship between various factors that when combined with stress result in mental illness. These psychological factors include:

- Developmental stages as defined by separate theory such as Eriksonian developmental stages;

- Childhood trauma such as child abuse, neglect, family disruption;

- Attachment, whether it is avoidant, secure or anxious;

- Worldview (disposition), be it optimistic, pessimistic, nihilistic or neurotic; and

- Personality, be it influenced by cluster A, B or C personality traits, tendencies 
or disorders.

The stress diathesis model postulates that a person with more factors has higher vulnerability and requires less stress to develop a mental illness, in a kind of Vulnerability times Stress type of model.

Figure 5. Representation of the stress diathesis model, showing some of the significant potential psychological diatheses (vulnerabilities)

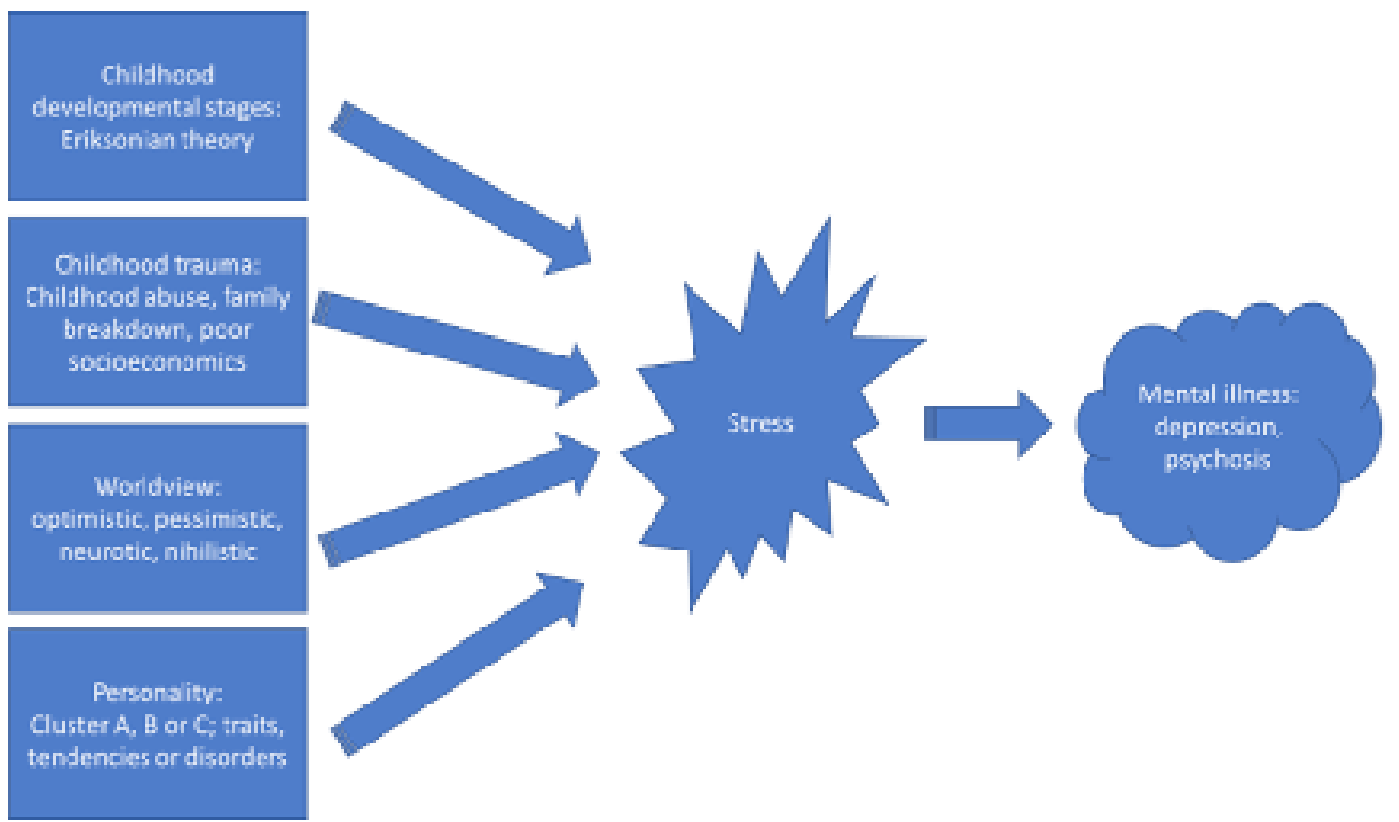

Source: Various created to grpahcially illustrate points above

Under health and safety laws and the world of case law that has emerged in its interpretation, the organisation's systems and processes must be so robust as to protect the careless, inadvertent and negligent worker. There is also an expectation that risk assessments performed in effectively implementing the mandated health and safety risk management approach (and control measures identified and implemented following that risk assessment) will take into account the nature and characteristics of the individuals that make up the workforce. Indeed, there is a particular regulation that requires organisations to ensure that control measures are working effectively and maintain their effectiveness over time. From the workers compensation perspective, there is an oft-cited principle referred to as the egg-shell psyche principle (modified from the tort law eggshell skull rule). Under the principle, a worker's erroneous perception of actual events can still give rise to a compensable injury and organisations are required to take the worker as they find them. A worker may have any combination of the vulnerabilities. However, they may have been able to function relatively well as they did not have a sufficient stressor for the vulnerability to develop into a full mental illness, e.g., they may have been neurotic but not sufficiently stressed to develop Major Depressive Disorder or Somatoform Disorder. 


\section{STRESS AS AGGRAVATION TO MENTAL ILLNESS}

Much like the stress diathesis model indicates that a vulnerability may become a mental illness with the addition of stress, so too may a well-controlled and managed or even recovered mental illness resurface or deteriorate. This includes mental illnesses such as mood disorders, anxious disorders and personality disorders. If a person has a diagnosable mental illness then, in most countries, they are protected under law as having a disability, e.g., Disability Discrimination Act in Australia and the Americans with Disability Act. However, such legal protection does not ameliorate the potential for stress to aggravate their diagnosis. It is not merely possible, but rather, reasonably foreseeable that in times of stress people who have a diagnosed condition are likely to be affected and it is illegal to discriminate against them for this. What is possible is to manage the stress well for the person so that the likelihood of the stress affecting them, and thereby aggravating their known condition, is minimised.

\section{DIRECT STRESS MENTAL ILLNESSES}

The third category of mental illness is a unique set of conditions. In the newest edition of the Diagnostic and Statistic Manual $5^{\text {th }}$ Edition (DSM-5) (2013) they have been gathered together in their own chapter. What is unique about these conditions is that we, the mental health scientific community, actually know for certain what causes them. Sadly, something that cannot be said of many of the other mental illnesses at this time. What is also unique is they are all caused by stress or trauma. No one without an event spontaneously gets Post Traumatic Stress Disorder. Unlike say Major Depressive Disorder which people do, without any known event, get it. These disorders include Adjustment Disorder, Adjustment Disorder with anxiety, Adjustment Disorder with depressed mood also known as reactive depression, Adjustment Disorder with mixed mood, Adjustment Disorder with disturbance of conduct, Acute Stress Disorder and Post Traumatic Stress Disorder (PTSD). While most workers may be subjected to stress at this time, less will be subjected to a traumatic event sufficient to trigger PTSD. Of course, we can expect that the frontline workers in essential services (particularly in the health care and aged care industries) are likely to be more at risk in this regard in the context of COVID-19.

\section{BUSINESS WITH COVID (BWC)}

Throughout March 2020, the world of work in Australia underwent a mass upheaval of its arrangements. As daily announcements were made by the Prime Minister of Australia, the Health Minister, State Premiers and their various Chief Medical Officers, businesses, recognising their obligations to take a proactive risk management approach, began to implement their crisis management plans with the vast majority of businesses voluntarily moving to working from home arrangements wherever it was practicable to do so. Interestingly, vast numbers of organisations undertook these moves without mandatory directives from Government.

In Australia, the Government responses have been staggered and have differed 
from State to State with staged restrictions being introduced firstly regarding travel (and self-isolation requirements for those who have been travelling overseas) and then across different industries (with specific guidance for healthcare, aged care, air transport, maritime industries among others), then a focus on restrictions for popular areas of public gathering (for example cinemas, restaurants and cafes), then restrictions on personal services providers (such as spas and beauty services), followed by limits on the numbers of people permitted to gather together in public (at first up to 10 and most recently a 2 person rule for gatherings either in public or in the home unless gathering with one's own household) and guidance being issued on maintaining social distancing (1.5m and $4 \mathrm{sqm}$ rules being communicated as guidance).

Australia's Federal system has made communication in this time of crisis somewhat confusing for individuals and businesses to follow as the Prime Minister of Australia (following meetings of a National Cabinet made up of both Federal and State leaders) has made various pronouncements from the podium but the matters subject of those pronouncements must be enacted at the State level (usually through public health orders under public health or public emergency acts) to have any legal effect. Of course, as is the way in a Federal system, each State and Territory has its own issues and implemented various aspects of the guidance in different ways. Most recently, public orders now require individuals to remain in their place of residence unless they have a reasonable excuse. Reasonable excuses include obtaining food or other goods and services, travelling for the purposes of work or education, exercise or medical or other caring reasons. One recent difference to emerge in this respect is visiting a partner that does not live with you is considering 'caring' in New South Wales but is not permitted in Victoria. There are hefty fines for breaching the public health orders and a ramped up police presence to enforce them in the States with the most confirmed coronavirus cases.

While those public orders still enable travel for the purposes of work attendance, most organisations have transitioned to mass working from home where it is possible for them to do so, operating with skeleton staff in their offices.

While keeping up with the constantly updated and differing Government specific guidance and orders has become a full time job, the reality is that the health and safety legal obligations for businesses in Australia have not changed in their fundamentals. Organisations still owe the primary duty to ensure the health and safety of workers so far as is reasonably practicable. They must still adopt a risk management approach and that goes for dealing with and effectively managing emerging hazards and risks (including pandemics such as COVID-19) as they impact particular businesses operations and their workers.

A number of regulators have issued statements of regulatory intent at this time noting that they will take a sensible and practical approach to technical non-compliance issues (such as meeting record-keeping requirements or conducting emergency drills in now empty offices), however they have taken the opportunity of re-iterating the importance of proactively managing the risks that COVID-19 poses in discharging their health and safety obligations which includes both managing the workplace environments in terms of infection control and managing the flow on effects of the new 
normal with BWC involving mass working from home arrangements.

Now working from home becomes the norm, and in the context of a pandemic and virtual shutdown (if not actually declared), all organisations must manage the risks that arise in this specific context. And this means appreciating that the home is now the workplace when the organisation's workers are at work.

For organisations participating in the mass working from home experiment, the working context has now completely changed and the basis upon which risk assessments were previously performed is now invalid. Health and safety laws require the review and revision of control measures where circumstances have changed. This would be one of those moments.

For example, the social distancing and social isolation requirements being imposed by Governments as measures to manage and prevent the spread of the coronavirus will have natural flow on effects in terms of additional or different hazards and risks for workers during the course of work. But there is not a one size fits all answer to the question as each worker will come with their own vulnerabilities and attributes as outlined above. We know there is a link between social isolation and loneliness. We know that loneliness can lead to negative mental health outcomes. This will be an area where organisations and their leaders will be required to exercise some leadership but the normal approach to the levers (training, calming, accommodation, procedures, variation and alignment) also goes out the window!

Risk assessments in the context of mass working from home (and the natural flow on effects for mental health) will require organisations to consider the nature of their business (and how it may have changed given the flow on effects of the pandemic), the consequences and flow on effects of the various Government orders but also to have a greater and more holistic understanding of their people. Understanding what someone's home life is like will be important to proactively managing mental health and wellbeing of workers through the pandemic as individuals in Australia are now effectively required to remain in their homes with limited exceptions. This will impact different cohorts within your workforce differently. For some, time at work will be blended with simultaneously performing other activities (such as supervising children at home whilst they are also transitioning to online learning arrangements) while for others, the social isolation will be extreme.

Organisations will need to take particular care with respect to workers living alone. This was already an issue lurking in the community at large. A joint study between the Australian Psychological Society and Swinburne University in 2018 identified that one in four Australians reported feeling lonely at least one day per week. It was what commentators were already calling a loneliness epidemic. Loneliness is the feeling of distress people experience when their social relations are not as they would like them to be. Our public health arrangements to combat COVID-19 will absolutely further exacerbate that situation. Australia's Commonwealth Government has recognised this is an issue with recent announcements for a further AUD 74 million for mental health programs in recognition of these issues. That includes a dedicated coronavirus wellbeing support line to be delivered by a well-recognised Australian mental health organisation, Beyond Blue, for people experiencing stress and anxiety related to the 
pandemic. Given the surge on such support services, organisations will need to be supplementing such initiatives by implementing their own specific strategies to support worker mental health and welfare at this time.

Domestic violence is another issue that organisations will now need to contend with as a consequence of the blurring lines between work and non-work contexts. Only a limited number of organisations in Australia had implemented workplace policies regarding domestic violence prior to the pandemic. However, we know that this will be an increased risk faced by a portion of workers in the context of this pandemic. The Australian Human Rights Commission in 2014 estimated that domestic violence was an issue for around 800,000 women in Australia which translated to one in six female workers. This is no fringe issue.

For some, the social isolation protection measures for COVID-19 are tantamount to being locked up with perpetrators of violence. This issue has been officially recognised by Australia's Commonwealth Government with Australia's Prime Minister acknowledging a 75\% increase in google searches for domestic violence services over the last couple of weeks as he announced an additional AUD 150 million for the national domestic violence initiative. In one state, Victorian Police have indicated they have seen double the number of requests for domestic violence support in the past week. Victorian Police say they are seeing an entirely new form of abuse in homes. Perpetrators are telling their partners that they have the coronavirus so that their partners cannot leave the house for any reason whatsoever (as they would be required to follow the directions to self-isolate for such cases). And as the home now becomes the place where work is performed, from the organisational perspective, it is possible that domestic violence will now actually be occupational violence. There is no longer the divide between the public sphere of work and the private sphere of the home.

You will recall from the introduction that organisations owe health and safety duties to workers when they are at work wherever it is that they are performing that work. As such, a partner perpetrating acts of domestic violence in the home while the worker is performing work has a sufficient nexus to the world of work. While many of those acts no doubt constitute various criminal offences under general criminal laws, they would also constitute offences under work health and safety laws in this context. The perpetrator would be considered an 'other person' for the purposes of the health and safety laws, being required not to adversely affect the health and safety of others (in this case, the worker) while at work. Given there is now a likely nexus with work, there would also be an expectation from health and safety regulators that organisations develop and implement a systematic way of doing what is reasonably practicable to identify and manage these risks, providing support for workers who may find themselves in these unacceptable situations. In conducting mental health impact assessments and risk assessments, organisations need to acknowledge and treat these reasonably foreseeable and known risks.

\section{PRACTICAL RECOMMENDATIONS FOR REMOTE WORKING THROUGH BWC}

All organisations need to conduct COVID-19 mental health impact assessments in 
adopting the mandatory proactive risk management approach required by Australia's health and safety laws. Mental health impact assessments need to work through what are the likely impacts on an organisation's workforce in terms of the mass working from home and consider the appropriate strategies the organisation needs to implement for workers as they work through the likely impacts on different cohorts within the workforce population. This requires organisations to have a consistent and clear approach but also multiple tailored initiatives that contemplate various types of 'home life' of their workers.

In deploying strategies for managing remote working through COVID-19 organisations need to prioritise:

Establishing, maintaining and improving rapport through BWC: in particular organisations need to emphasise the importance of maintaining team rapport and cohesion with team leaders. Operational leadership at all levels becomes critical here. Organisations need to support resilience at the organisational, departmental, team and individual levels. Many of the practical suggestions below are essentially about establishing maintaining and increasing rapport.

Leadership and communications in establishing and maintaining rapport: with working from home, there is a real tendency to drift into relying on written communications backed up by phone calls. What those modes of communication miss is the world of non-verbal cues that are so critical in being able to check-in on how people are really feeling. As such, organisations need to invest in multiple mechanisms to "get eyes on their people". Video-conference facilities such as Cisco Webex, Bluejeans and Zoom have become invaluable to people at this time. Similarly, making sure that communications are not just about work. Maintaining the social aspect of work while performing remotely is also critical. A number of social media applications have been deployed by teams across Australian businesses in that regard (some have created Whatsapp groups for banter, others are using applications like Houseparty and creating Facebook groups). Recognise that you may need to 'switch it up' on occasion as the novelty wears off and use leadership at various levels to keep the use of these mechanisms alive.

Supporting and encouraging routine: Human beings crave certainty and predictability. A pandemic such as COVID-19 takes certainty away from us at a macro level. Organisations need to create conditions for some level of predictability and routine to provide some certainty. Considering how you maintain your usual rituals (such as your usual times for team meetings or your usual team social rituals (albeit as those rituals are taken into a virtual context)) may be a way of providing such comfort and a little certainty.

Managing the risk of burnout: Burnout is in fact an Adjustment Disorder. All Adjustment Disorders are a reaction to a stressor that causes clinically significant levels of distress and dysfunction. With burnout the stressor is workplace stress. 
This, like any Adjustment Disorder, can be accompanied by changes to mood and anxiety responses. As the work and non-work environment are blurred, so too are working hours, compromising boundaries (which is one of the key factors in resilience discussed above). There is a tendency not to know when to start and finish when working from home and as such, a corresponding risk of burnout. Leadership communications on expectations is important here. Find a way of collectively coming together to open and close out the day - essentially setting the expectations and priorities for the day, getting people to "switch on" and then giving people permission to log off and to recognise the accomplishments of the day. That might be a quick stand up video conferencing team meeting at an appointed time at the beginning of the day - helping people to focus on their priorities and then closing the day with an end of day beverage to de-brief.

Avoid the temptation to micro-manage: Whenever there is loss of control, there is a desire to find some way of gaining it back. From a leadership perspective, we will often see people lean into micro-management during such moments of crisis. Of course it will be important for leaders to keep an eye on business objectives and achievements against those objectives at this time but look to avoid micromanaging as a result. Leaders need to lead from trust and seeing their people as the solution, not the problem. Empower and encourage people to find the new inventive ways of achieving the team goals through the challenging circumstances, as this will also increase both individual and organisational resilience.

Looking after physical health: Organisational and leadership communications should include tips for looking after physical health throughout this period. This draws on the physical self-efficacy described above. We know just how important it is to protect sleep for maintaining a positive state of psychological health. Sleep also helps the immune system with research indicating that sleep is important for helping T cells in the body to fight off infection. Getting enough rest and sleep will be particularly important during this time. Organisational communications should highlight the importance of sleep and rest to workers. We also know that a significant source of stress management for Australians is the gym workout. Our approach to physical exercise may need to change with gym closures and social distancing on gatherings but that does not mean not getting any physical exercise. Teams can support each other with innovative physical exercise challenges that can still be done in the comfort of one's own home or whilst exercising social distancing and be another point of interaction for rapport and team cohesion. These sorts of team exercise programs can also encourage people to take breaks in the middle of the day, which can also increase productivity and cognitive functioning.

Mindfulness: There is a world of health benefits of meditation. Many organisations supported health and wellbeing promoting meditation and yoga programs (yoga includes the sensory modulation and Yerkes Dodson arousal modulation elements as well as mindfulness) in their workplaces before BWC. Less discussed 
in the world of work is the importance of music for health and wellbeing. Studies have actually compared the benefits of music to meditation and found both practices were linked to significant improvements in mood and sleep quality, having powerful benefits for overall health and wellbeing. Studies have also shown that music can have positive effects on mood, have positive effects on depressive symptoms, can lower levels of stress-related hormones like cortisol and ease pain. Finding ways to encourage engagement with music can assist individuals with maintaining emotional self-efficacy, sensory modulation and arousal modulation. It also is another touch point for rapport. Sharing music videos, talking to one another about favourite music, developing a shared playlist in a music streaming service may all be simple ways of organisation's encouraging that kind of active engagement with music.

Supporting your leaders: Some leaders will have natural instincts towards these types of activities. Other leaders may not. While authenticity is key, organisations should be giving practical guidance to leaders on what to watch out for and what to think about in implementing strategies to maintain rapport. They may also need guidance on how to communicate from a place of empathy and acknowledgement of the collective experience so that they can support workers in maintaining a positive challenge mindset, how to expect and experience change and uncertainty, how to tolerate discomfort and adapt to changing circumstances and also to recognise the need for re-prioritisation of expectations (an acknowledgement of the new normal). Have your leaders acknowledge their own vulnerability in this situation and share with their people what is helping them to get through the situation. This develops the person's determination and emotional self-efficacy described above. That will, in turn, give workers a signal that sharing struggles is accepted and expected at this time, normalising the experience of the difficulty and the disclosure to others to gain support and assistance.

Accentuate the positive: There is a plethora of crisis news right now. Everywhere you turn it is a negative story. Organisations need to counter some of this with the positive stories that no doubt exist that are making it possible for the mass remote working experiment to succeed. Take moments (large and small) to acknowledge the great work people are doing and to recognise it in front of their peers. Have staff reflect on what they did to contribute to bringing about that positive event, this bolsters their general self-efficacy and decreases alienation. The positive also snowballs, achieving success and reflecting on it, and increases the chance of it happening again.

FUNDING: This research received no external funding.

CONFLICT OF INTEREST: The authors declare no conflict of interest.

ACKNOWLEDGEMENTS: We would like to thank all the workers around the world operating on the frontlines in healthcare, emergency services and other essential services for their dedication to their 
essential roles during the COVID-19 pandemic.

\section{REFERENCES}

American Psychiatric Association. 2013. Diagnostic and statistical manual of mental disorders (5th ed.). https://doi.org/10.1176/appi.books.9780890425596

Americans With Disabilities Act of 1990, Pub. L. No. 101-336, 104 Stat. 3281990.

Attorney General's Department v K. 2010. NSWWCPD 76

Australian Psychological Society. 2018. Australian loneliness report: A survey exploring the loneliness levels of Australians and the impact on their health and wellbeing. Melbourne: APS. https://researchbank.swinburne.edu.au/items/c1d9cd16-ddbe417f-bbc4-3d499e95bdec/1/

Besedovsky, Luciana, Tanja Lange, \& Jan Born. 2012. "Sleep and immune function.” Pflugers Arch - Eur J Physiol 463: 121-137. https://doi.org/10.1007/s00424011-1044-0

Csikszentmihalyi, Mihály. 1975. Beyond boredom and anxiety. San Francisco: JosseyBass Publishers.

Csikszentmihalyi, Mihály. 1991. Flow: The psychology of optimal experience. New York: Harper Collins.

Csikszentmihalyi, Mihály. 1996. Creativity: Flow and the psychology of discovery and invention. New York: HarperCollins Publishers.

Csikszentmihalyi, Mihály. 1997. Finding flow: The psychology of engagement with everyday life. New York: BasicBooks.

Diagnostic and Statistic Manual 5 ${ }^{\text {th }}$ Edition (DSM-5). 2013.

Disability Discrimination Act. 1992. (Cth)

Gearin, Mary and Ben Knight. 2020."Family violence perpetrators using COVID-19 as 'a form of abuse we have not seen before'." $A B C$ News March 29. Retrieved April 1, 2020 (https://www.abc.net.au/news/2020-03-29/coronavirus-family-violence-surge-in-victoria/12098546).

Hassan, Arfi \& Forbis Ahmed. 2011. "Authentic Leadership, Trust and Work Engagement.” World Academy of Science, Engineering and Technology 5(80): 750-756.

Innes, Kim E. et al. 2016. "Effects of Meditation versus Music Listening on Perceived Stress, Mood, Sleep and Quality of Life in Adults with Early Memory Loss: A Pilot Randomized Controlled Trial.” Journal of Alzheimer's Disease 52(4): 1277-1298. DOI: $10.3233 / J A D-151106$

Lindsay $v$ IMB Ltd. 2019. NSWWCCPD 7

Miller, Scott D., Barry L. Duncan, \& Mark A. Hubble. 1997. Escape from Babel: Toward a unifying language for psychotherapy practice. New York: Norton.

Prime Minister of Australia. 2020. Media release: $\$ 1.1$ billion to support more mental health, Medicare and domestic violence services, 29 March 2020. Retrieved April 1, 2020 (https://www.pm.gov.au/media/11-billion-support-more-mental-health-medicare-and-domestic-violence-services-0).

Safe Work Australia. 2015. Work-Related Mental Disorders Profile 2015. Retrieved April 1, 2020 (https://www.safeworkaustralia.gov.au/system/files/documents/1702/ 
work-related-mental-disorders-profile.pdf).

Safe Work Australia. 2018; 2019. Work-related psychological health and safety: A systematic approach to meeting your duties, national guidance material. Retrieved April 1, 2020 https://www.safeworkaustralia.gov.au/doc/work-related-psychological-health-and-safety-systematic-approach-meeting-your-duties

Safety Institute of Australia. 2018. Media Release: Call for wider national action on Harassment, Bullying and Abuse in the workplace, 8 March 2018. Retrieved April 1, 2020 (https://www.aihs.org.au/news-and-publications/news/media-release-call-wider-national-action-harassment-bullying-and-abuse-in).

Suda, Miyuki, Kanehisa Morimoto, Akiko Obata, Hideaki Koizumi, \& Atsushi Maki. 2008. "Emotional responses to music: towards scientific perspectives on music therapy.” Neuroreport 19(1): 75-78. doi:10.1097/WNR.0b013e3282f3476f.

Work Health and Safety Act 2011 (NSW)

Work Health and Safety Regulations 2011 (NSW)

Yerkes Robert M. \& John D. Dodson. 1908. "The relation of strength of stimulus to rapidity of habit-formation." Journal of Comparative Neurology and Psychology 18(5): 459-482. doi:10.1002/cne.920180503.

\section{BIOGRAPHICAL NOTE}

Paul A. Phillips (PhD, University of Sydney) is Founder and Psychologist at Need a Psych, Director \& Chief Mental Health Officer at Suremploy and Founder \& Psychologist at The Greyscale.

Alena Titterton (LLB (Hons), B Beh Sci (Psych), Grad Dip Leg Prac (With Distinction), Griffith University) is a partner at Clyde \& Co where she specialises in health, safety and security matters globally, based in Australia.

Michael Tooma (BComm, LLB (Hons), LLM, Fellow of Australian Institute of Health and Safety) is the Global Head of Health and Safety at Clyde \& Co and the Managing Partner of its Australian operations.

OPEN ACCESS: This article is distributed under the terms of the Creative Commons Attribution Non-commercial License (CC BY-NC 4.0) which permits any non-commercial use, and reproduction in any medium, provided the original author(s) and source are credited.

ARTICLE HISTORY: Received 2020-04-06 / Accepted 2020-04-11 